\title{
Research and evaluation of innovative integrated industrial structure potential: theoretical and practical aspects
}

\author{
S.V. Zdolnikova ${ }^{1, *}$, A.V. Babkin ${ }^{1}$, and N.B. Smolskaya ${ }^{1}$ \\ ${ }^{1}$ Peter the Great St.Petersburg Polytechnic University, 195251, Polytechnicheskaya str., 29, St.Petersburg, the Russian Federation
}

\begin{abstract}
Modern market conditions, as well as the reorientation of the Russian economy from raw materials to the innovative model of development, based, in particular, on strengthening the position of domestic industry being able to compete against the international producers, are the incentives to seek ways to increase efficiency and create additional competitive advantages that at present are innovative products and services. One of the innovative economic entity development factors is the establishment and effective use of its innovative potential. The innovative potential evaluation plays an important role in the development of innovation policy and innovation strategy of market subject activity. This article investigates the innovative potential of the integrated industrial structures (IIS) that presently are one of the most promising forms of economic entities integration. The authors propose an approach to the definition and assessment of innovative IIS potential, as well as the comprehensive and systemic innovative potential estimation procedure. The developed theoretical and methodological provisions were applied to evaluate the innovative potential of the JSC Svetlana, one of the leading Russian electronic instrument engineering holdings.
\end{abstract}

\section{Relevance of the study}

The creation of IIS is nowadays one of the current trends of the economic transformations in the Russian economy. Thus, within the period from 2011 to 2015, the average transaction share in the industrial sector amounted to $31 \%$, with the most actively integrated sectors being oil and gas industry, metallurgy and mining. When being integrated, enterprises are able to respond more flexibly to demand changes, and joint production contributes to the various technical product quality increase on the basis of a systemic use of intellectual potential and also allows to save resources and to obtain a synergetic effect [1]. These circumstances contribute not only to the production increase, but also to the development of high-tech innovative products, which leads to increased innovation performance of IIS and industry sectors on the whole.

One of the innovative economic entity development factors is the establishment and effective use of its innovative potential. The innovative potential evaluation plays an important role in the development of innovation policy and innovation strategy of market subject activity. High innovative potential is the primary means of IIS successful adaptation to the uncertain and rapidly changing environmental conditions and it ensures the formation and implementation of such development schemes that will lead to the optimal outcomes in the specific situation.

\section{Problem statement}

To develop the IIS innovative potential evaluation tool as well as to explore the practical aspect of its application on the basis of the integrated structure essence research and its innovative potential analysis. In order to achieve this goal the following objectives are stated:

to define the "innovative economic entity potential" concept

to develop the approach to the essence presentation and to the innovative IIS potential evaluation

to develop the innovative IIS potential evaluation procedure

to apply the developed evaluation procedure for the innovative potential evaluation of the industrial holding JSC "Svetlana".

\section{Results of the study}

\subsection{The "innovative economic entity potential" concept}

The innovative potential is a complex and multifaceted category that has been discussed by the foreign and domestic scholars since the third quarter of the 20th century. The development of this economic category is connected with the concepts of "economic potential", "scientific and technical potential", etc. Conducted by 
the authors the analysis of approaches to the innovative potential understanding characterizes it as the combination of different kinds of capacities or resources, i.e. the set of certain forces that should guarantee the successful management of innovation to the economic entity $[2,3,5,7,8]$.

However, the mere existence or absence of such forces does not guarantee effective innovation outcomes, thus the innovative potential should be considered as the economic entity ability with the resources available to achieve maximum innovation outcomes [12, 15, 17, 19]. As the indicator of the innovation activity development level, innovative potential should reflect the effectiveness of innovation development and implementation into the market or into the operating activities of the economic entity, and, therefore, needs to include the resources and the management basis for the creation of innovative goods (construction, services) and to take into account internal and external conditions favorable or unfavorable to their commercialization.

Based on the foregoing, the authors propose to consider the innovative potential as the skills and opportunity of the economic entity to convert the available resources into the innovation outcomes. This approach is based on the evaluation of three main elements (fig. 1):

1) resources as the material basis for the innovation activity implementation;

2) skills, i.e. the know-how to translate available resources into the innovation outcomes (innovation goods, construction, services) that are proposed to be evaluated through the concrete results of innovation activity;

3) opportunities, i.e. the presence of favorable or unfavorable trends in the development of innovation economic entity activity.

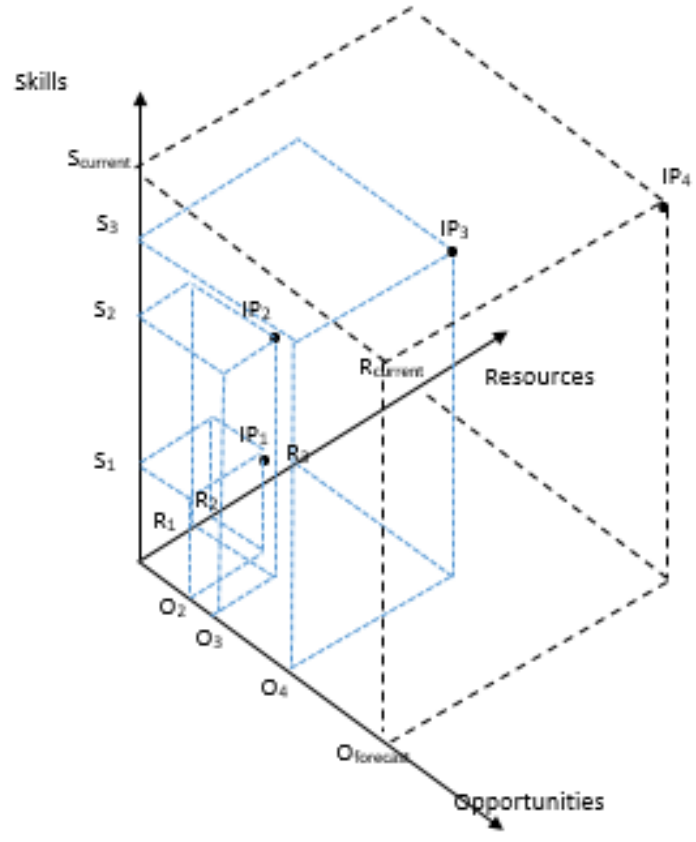

Fig. 1. The innovative economic entity potential in the coordinate system "Resources-Skills-Opportunities".
The difficulty to define the innovative IIS potential is related to the ambiguity of the IIS consideration: on the one hand, it is regarded as a sole structure comparable to the enterprise (the natural integration principle), on the other hand, it is considered as a set of formally independent enterprises involved into the joint operation activity (the quasiintegration principle). From the point of view of the system approach applied by the author to determine the IIS nature, this fact can be explained by two related patterns: progressive systematization and progressive factorization.

\subsection{The approach to the essence presentation and to the innovative IIS potential evaluation}

The authors considered two variants of innovative IIS potential evaluation:

1) the innovative IIS potential is considered as the IIS ability and opportunity as a whole to convert the available resources into innovation outcomes, in this case IIS is comparable to the enterprise (the natural integration principle), and the integrity coefficient $\alpha$ is measured within the range from 0.94 to $1(0.94<a<1)$;

2) the innovative IIS potential is considered as a set of innovative capacities of the enterprises included in the IIS, i.e. as a set of abilities and opportunities of the organizations included into the IIS, to convert available resources into innovation outcomes, in this case the IIS is formed on the quasiintegration principle, and the integrity coefficient $\alpha$ is measured within the range from 0.5 to $0.94(0.5<\mathrm{a} \leq 0.94)$.

Thus, the innovative IIS potential is the total potential of the economic entities involved in the IIS that is generated with regard to the structural integrity, as well as to the synergetic effect emerging in it and reflects the IIS ability and opportunity to convert the available resources into innovation outcomes.

The approach to the innovative potential definition and evaluation allows not only to characterize the innovative economic entity development level within a specific period of time, but also to reflect the trend of its change, thereby presenting innovative potential as the integral indicator in the coordinate system "ResourcesAbilities-Opportunities" with regard to the structural integrity degree and to the synergetic effect occurring in it. This approach provides a comprehensive view of innovative potential making it possible to fully reveal its nature.

\subsection{Innovative IIS potential evaluation procedure}

The innovative IIS potential evaluation procedure provides the determination of the IIS innovation activity development level. It includes the developed approach and stages of innovative potential evaluation, the synergetic effect evaluation procedure, the algorithm of IIS innovative potential evaluation and the algorithm for calculating the IIS innovative potential integral index. The innovative IIS potential evaluation procedure consists of three stages: 
1) the preparatory stage including the identification of the IIS integration type, the choice of indicators for evaluating the components of the innovative IIS potential and its normative values determination.

2) the evaluation stage including the calculation of individual and integrated indicators of the innovative potential, determination of the synergetic effect, the calculation of the innovative IIS potential integral index;

3 ) the final stage including the innovative IIS potential level definition; the development of proposals to improve the innovative IIS potential level.

The preparatory stage begins with the IIS integration type identification on the basis of the integrity coefficient $\alpha$ calculation. Under the proposed approach, depending on the $\alpha$ value the innovative IIS potential is defined either according to the structure as a whole or as the sum of the innovative economic entities capacities included into the IIS.

The choice of indicators for evaluating the innovative IIS potential components is a crucial step of the preparatory stage. The scorecard should $[14,16]$ :

- provide a comprehensive evaluation of each innovative IIS potential component;

- include universal and easily comparable indicators that will evaluate the innovative potential of each entity included into the IIS as well as other IIS innovative potential;

- include available indicators contained in the IIS accounting, statistical, etc. reporting forms.

The final step at this stage presupposes the normative values identification for each selected innovative IIS potential indicator constituents.

The evaluation stage includes main calculations: separate indicators of the innovative potential constituent parts are identified, integral indicators of each component are calculated, synergetic effect is evaluated, as well as the value of the innovative potential integral indicator is defined.

The synergetic effect describes the IIS innovation activity efficiency increase due to the development of production and organizational relations among entities included into the structure $[6,9,11]$. If entities have partial autonomy and their innovation activities are carried out in cooperation with other entities as well as outside the IIS, a synergistic effect can be evaluated by comparing the effectiveness of the innovation outcomes that have been achieved by the entities independently and jointly $[10,13,18]$. In case the IIS is a sole structure and the entities included in it deprive of their independence, a synergetic effect will be taken into consideration in the IIS innovation activity results as the resources, abilities and opportunities of the entities will be considered not autonomous but jointly as well as their individual results.

Thus, it is reasonable to take a synergistic effect into consideration in those IIS where there is partial independence of the entities included into the IIS, i.e., at $0.5<\mathrm{a} \leq 0.94$.

At the final stage the innovative potential level is determined and the proposals for increasing it are developed. The innovative IIS potential level determination is done using scaling, i.e., assigning numerical values to certain states of the system under study, i.e. innovative potential. Scaling is necessary for bringing the integral index, which combines a large number of diverse indicators, to the only possible interpretation of its value.

The procedure basis is the algorithm of innovative IIS potential evaluation. This algorithm is the combination and the order of entity actions required for obtaining accurate data on the innovative potential state (fig. 2).

The innovative IIS potential integral index is proposed to be evaluated as the arithmetic average of the innovative potential with regard to the integrity coefficient $\alpha$ and the synergetic effect value.

The formulas for calculating the innovative IIS potential integral index are presented in table 1 .

Table 1. Formulas for calculating the innovative IIS potential integral index.

The formula for calculating the integral indicator of innovative potential of IIS

1. The coefficient of consistency: $0,5<a \leq 0,94$ short term

1) $I P_{I I S}=\sum_{i=1}^{n} \frac{I_{\text {resources } i}+I_{\text {resulting }_{i}}+I_{a b i}}{3} \times a \times S E$,

if $\sum_{i=1}^{n} \frac{I_{\text {resources } i}+I_{\text {resulting }_{i}}+I_{a b_{i}}}{3}>0$;

2) $I P_{I I S}=\sum_{i=1}^{n} \frac{I_{\text {resources } i}+I_{\text {resulting }_{i}}+I_{a b i}}{3} \times \frac{1}{a} \times \frac{1}{S E}$,

if $\sum_{i=1}^{n} \frac{I_{\text {resources } i}+I_{\text {resulting }_{i}}+I_{a b i}}{3}<0$;

1) $I P_{I I S}=\sum_{i=1}^{n} \frac{I_{\text {resources } i}+I_{\text {resulting }_{i}}+I_{a b i}}{3} \times a \times S E^{l}$,

if $\sum_{i=1}^{n} \frac{I_{\text {resources } i}+I_{\text {resulting }_{i}}+I_{a b_{i}}}{3}>0$;

2)

$I P_{I S S}=\sum_{i=1}^{n} \frac{I_{\text {resources } i}+I_{\text {resulting }_{i}}+I_{a b i}}{3} \times \frac{1}{a} \times \frac{1}{S E^{l}}$

if $\sum_{i=1}^{n} \frac{I_{\text {resources } i}+I_{\text {resulting }_{i}}+I_{a b_{i}}}{3}<0$;

\begin{tabular}{|l|}
\hline 2. The coefficient of consistency: $0,94<a<1$ \\
\hline
\end{tabular}

1) $I P_{I S S}=\frac{I_{\text {resources } i}+I_{\text {resulting }_{i}}+I_{a b i}}{3} \times a$,

if $\frac{I_{\text {resources } i}+I_{\text {resulting }_{i}}+I_{a b i}}{3}>0$,

2) $I P_{I S S}=\frac{I_{\text {resources } i}+I_{\text {resulting }_{i}}+I_{a b i}}{3} \times \frac{1}{a}$, 


$$
\text { if } \frac{I_{\text {resources } i}+I_{\text {resulting }_{i}}+I_{a b i}}{3}<0
$$

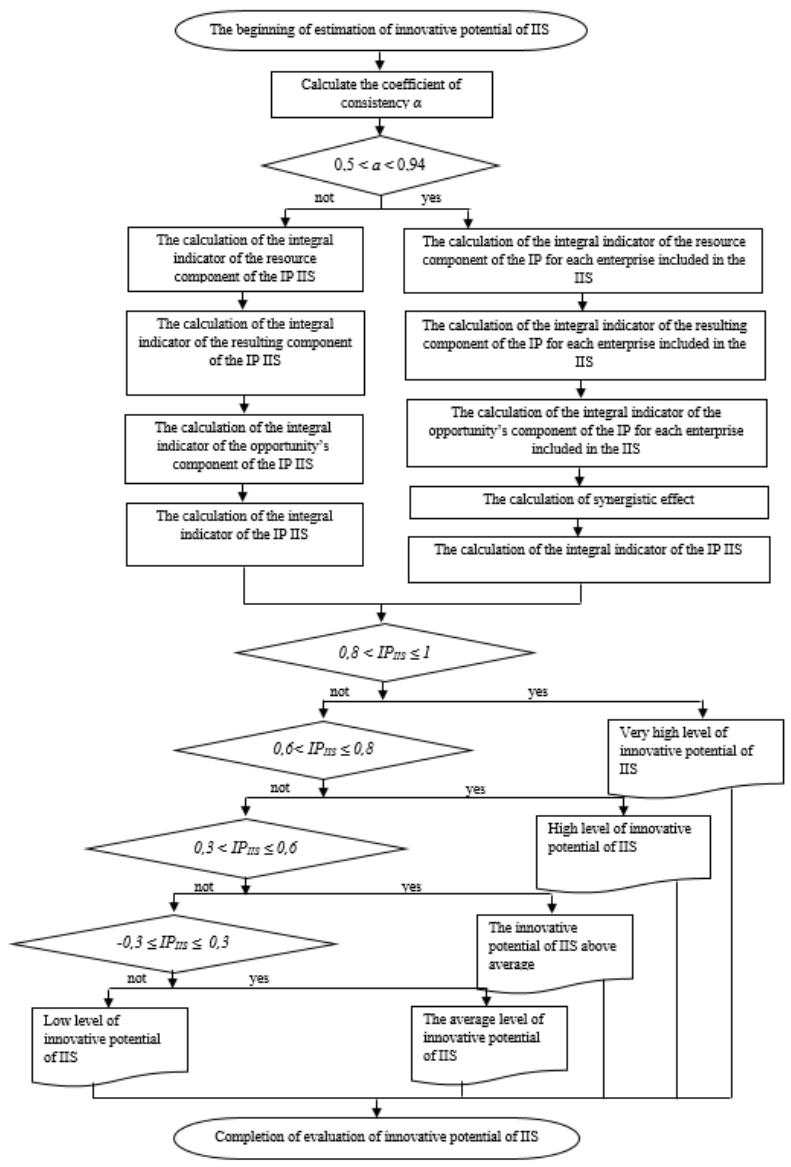

Fig. 2. The algorithm of the innovative IIS potential evaluation.

The innovative IIS potential integral index characterizes the innovative potential value in points, which allows to obtain an objective evaluation based on the use of quantitative indicators covering the main aspects of innovative IIS development.

The developed innovative IIS potential evaluation procedure makes it possible to compare and analyze the level of innovation potential of a single IIS as well as of several IISs through the use of relative indicators. This circumstance facilitates the bottleneck identification, the elimination of which will allow to obtain new competitive advantages and will contribute to stable economic and innovative IIS development.

\subsection{Application of the developed evaluation procedure for the innovative potential evaluation (on the example of the industrial holding JSC "Svetlana")}

The innovative IIS potential research was carried out on the example of the holding JSC "Svetlana". The holding JSC "Svetlana" (hereinafter - the Holding) has been operating in the market of electronic industry in Russia for more than 125 years. During this time its manufacturing activity has evolved from the incandescent lamps production to the production of unique nanoheterostructures and devices developed on their basis. The analysis shows that innovation activity of the IIS under consideration, on the whole, meets the requirements of the external environment prevailing in the new economy and articulated in the State industrial and innovation policy.

In a number of indicators that characterize the innovative potential, the Holding exceeds the average development level of industrial enterprises operating in the engineering industries, however, the problematic component of the Holding innovative potential is the resulting component (fig. 3).

On the based of the conducted analysis the following proposal for the Holding innovative potential was elaborated, that is the Holding's own assets investment into the innovation activities. As the source for the Holding's own assets the retained earnings were considered $[4,20]$.

To predict changes in the innovative potential level depending on the amount of the Holding's own assets invested into the innovation activity development four scenarios involving the investment of various company's own assets were considered. The scenario assessment shows that annual investments of $50 \%$ of the total cost of research, development and innovation in 2015, i.e. 283141.3 thousand RUR, does not exceed $10 \%$ of retained earnings in 2015, will have allowed to raise the level of the integral index of the resulting component, and, with the invariable level of resources component, to increase the opportunity component integral indicator to the level of "very high" by 2020 (table 2). The effectiveness of the proposed practical recommendations on the Holding innovative potential development is presented in table 3 .

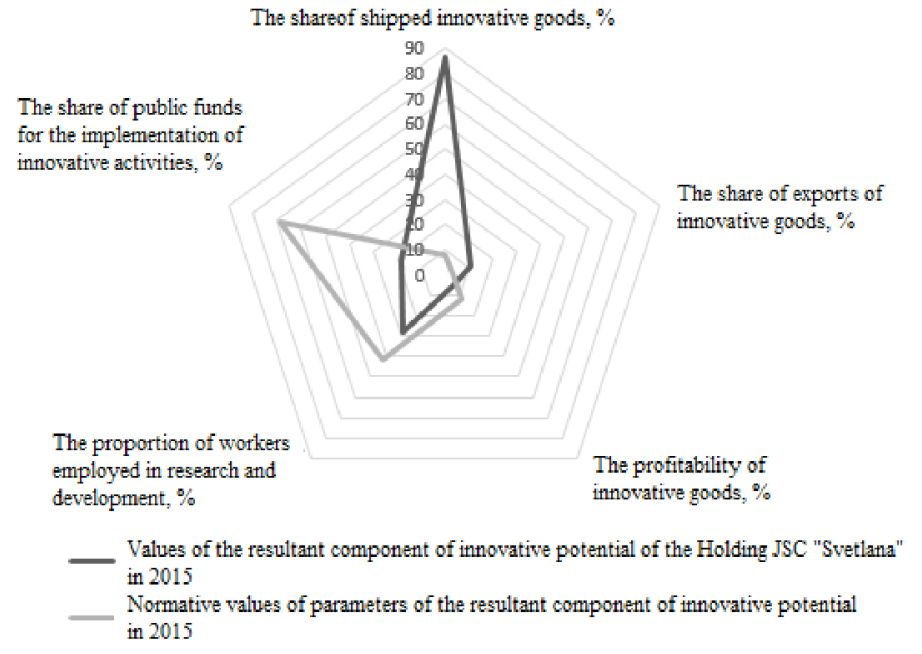




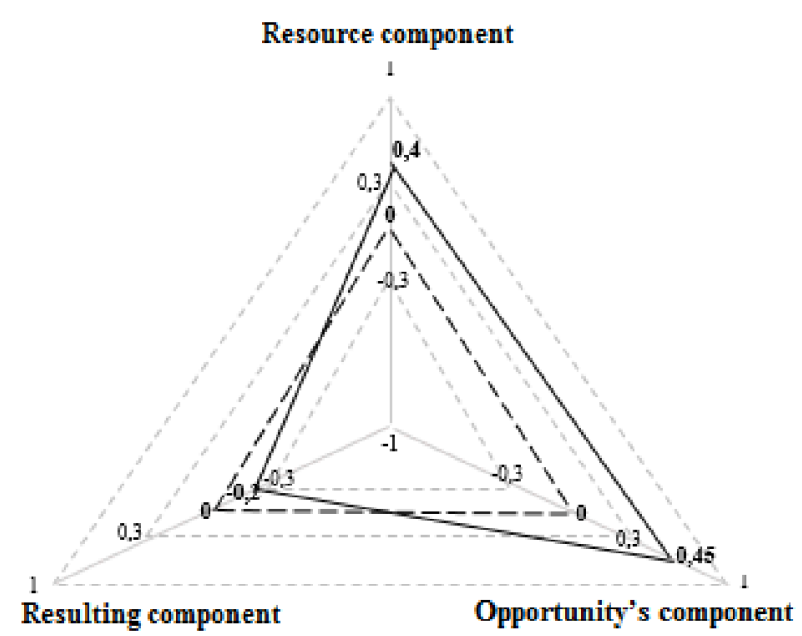

Components' scoring of the innovation potential of the Holding ISC "Svetlana" in 2015

- - - The average level of the components of the innovation potential in scores

Fig. 3. Analysis of the Holding JSC "Svetlana" development on the basis of the innovative potential.

Table 2. The results of the company's own assets additional investment on research, development and innovation scenarios implementation in 2016-2020.

\begin{tabular}{|c|c|c|}
\hline Indicator & Scenario 1 & Scenario 4 \\
\hline \multicolumn{3}{|c|}{2016} \\
\hline $\begin{array}{l}\text { The cost of research, } \\
\text { development and } \\
\text { innovation, thousand rub. }\end{array}$ & 662959,8 & 946101,0 \\
\hline $\begin{array}{l}\text { The volume of innovative } \\
\text { goods (works, services), } \\
\text { thousand rub. }\end{array}$ & 4176579 & 5479028,6 \\
\hline $\begin{array}{l}\text { The cost of the produced } \\
\text { innovative goods (works, } \\
\text { services), thousand rub. }\end{array}$ & 3940168,9 & 4789592,8 \\
\hline \multicolumn{3}{|l|}{$\begin{array}{l}\text { The profitability of } \\
\text { innovative goods }\end{array}$} \\
\hline$\%$ & 6 & 14,4 \\
\hline in scores & -1 & 0 \\
\hline \multicolumn{3}{|l|}{$\begin{array}{l}\text { The share of public funds } \\
\text { for the implementation of } \\
\text { innovative activities }\end{array}$} \\
\hline$\%$ & 37,7 & 26,4 \\
\hline in scores & -1 & -1 \\
\hline $\begin{array}{l}\text { The knowledge-intensive } \\
\text { innovative goods (works, } \\
\text { services), rub./rub. }\end{array}$ & 0,16 & 0,17 \\
\hline \multicolumn{3}{|c|}{2020} \\
\hline $\begin{array}{l}\text { The cost of research, } \\
\text { development and } \\
\text { innovation, thousand rub. }\end{array}$ & 1245384 & 1528525,3 \\
\hline $\begin{array}{l}\text { The volume of innovative } \\
\text { goods (works, services), } \\
\text { thousand rub. }\end{array}$ & 4884805 & 6187254,5 \\
\hline $\begin{array}{l}\text { The cost of the produced } \\
\text { innovative goods (works, } \\
\text { services), thousand rub. }\end{array}$ & 4608306,6 & 5457730,5 \\
\hline $\begin{array}{l}\text { The profitability of } \\
\text { innovative goods }\end{array}$ & & \\
\hline
\end{tabular}

\begin{tabular}{|l|l|l|}
\hline$\%$ & 6 & 13,4 \\
\hline in scores & -1 & 0 \\
\hline $\begin{array}{l}\text { The share of public funds } \\
\text { for the implementation of } \\
\text { innovative activities }\end{array}$ & & \\
\hline$\%$ & 24,4 & 19,9 \\
\hline in scores & -1 & 0 \\
\hline
\end{tabular}

Table 3. The effectiveness of the proposed practical recommendations on the Holding JSC "Svetlana" innovative potential development.

\begin{tabular}{|l|l|}
\hline \multicolumn{1}{|c|}{ Indicator } & \multicolumn{1}{c|}{ Result } \\
\hline $\begin{array}{l}\text { The resulting component of } \\
\text { innovative potential }\end{array}$ & $\begin{array}{l}\text { The increase in } 2 \\
\text { times }(0,4 \text { scores })\end{array}$ \\
\hline $\begin{array}{l}\text { The profitability of innovative } \\
\text { goods }\end{array}$ & $\begin{array}{l}\text { An increase from } 6 \% \\
\text { to } 13.4 \%\end{array}$ \\
\hline $\begin{array}{l}\text { The share of public funds for the } \\
\text { implementation of innovative } \\
\text { activities }\end{array}$ & $\begin{array}{l}\text { The decrease from } \\
24.4 \% \text { to } 19.9 \%\end{array}$ \\
\hline Innovative potential & $\begin{array}{l}\text { An increase of } 33 \% \\
(0,13 \text { scores })\end{array}$ \\
\hline $\begin{array}{l}\text { The volume of innovative goods } \\
\text { (works, services) }\end{array}$ & $\begin{array}{l}\text { An increase of } 27 \% \\
(1302,4 \text { million rub.) }\end{array}$ \\
\hline
\end{tabular}

The practical implementation of the developed proposals will enhance the innovative potential level and ensure the effective development of innovation activities and innovation sector of the Holding.

\section{Conclusions}

1. Based on the analysis of approaches to the innovative economic entity potential definition and evaluation it was proposed to consider the innovative potential as the sum total of the entity resources, abilities and opportunities to conduct innovative activities.

2. The approach to the understanding and evaluation of the IIS innovative potential representing it as the IIS ability and opportunity to convert the available resources into innovation outcomes as well as taking into account the integrity degree and the synergetic effect occurring in the integrated industrial structures synergistic effect was proposed.

3. The tools were developed for the IIS innovative potential evaluation including stages, algorithm and procedure. The IIS innovative potential evaluation will have three stages: the preparatory stage, which is aimed to determine the IIS integration type, to select the innovative potential components evaluation indicators and to define their normative values; the evaluation stage, which includes the calculation of individual and integrated indicators of the innovative potential components evaluation, the definition of synergetic effect and the calculation of the innovative potential integral indicator; the final stage, which determines the innovative potential level and develops proposals to increase the innovative potential level. The innovative IIS potential evaluation procedure allows to give an objective assessment and to ensure comparability of results as well as to consider such IIS features as the integrity and synergistic effect appearance. 
4. On the basis of the developed organizationaleconomic mechanism the IIS development research was conducted in the course of which the compliance of the state of innovation activity in the IIS under consideration with the requirements of the external environment prevailing in the new economy and articulated in the State industrial and innovation policy was stated, as well as practical recommendations on the Holding JSC "Svetlana" innovative potential development were worked out and their cost-effectiveness was evaluated.

\section{Call for further research}

The authors associate the future research directions with the modeling of the innovative IIS potential management as the integrated system of measures interacting with other subsystems and processes occurring in the IIS and contributing to the continuous innovative potential development.

\section{References}

1. G. Ahuja, C.M. Lampert, Strategic Management Journal, 22, 521-543 (2001)

2. A. Babkin, T. Kudryavtceva, S. Utkina, World Applied Sciences Journal, 28(10), 1408-1413 (2013)

3. A. Babkin, V. Plotnikov, S. Muraveva, Proceedings of The 25th International Business Information Management Association Conference, 1286-1294 (2015)

4. A.V. Babkin, S.V. Zdolnikova, Proceedings of The 28th International Business Information Management Association Conference, 1-11 (2016)

5. G. Bell, Strategic Management Journal, 26, 287-295 (2005)
6. G. Bysrtay, Journal of Cybernetics, 2, 71-88 (2003)

7. Y.T.H. Chiu, Journal of Business and Industrial marketing, 24, 46-55 (2009)

8. R. Cowan, N. Jonard, J. Zimmermann, Management science, 53, 1051-1067 (2007)

9. E.I. Galeeva, News of Orenburg State University, 8(114), 118-123 (2010)

10. E.V. Gusev, K.V. Kardapoltcev, Vector of science of Togliatti state University. Series: Economy and management, 2(5), 10-16 (2011)

11. G. Haken, Synergetics (Mir, Moscow, 1977)

12. M. Hobday, A. Davies, A. Prencipe, Industrial and Corporate Change, 14, 1109-1143 (2005)

13. L. Musaev, Bulletin of SRSTU(NPI), 3, 132-137 (2011)

14. A. Novikov, A. Babkin, Biosciences Biotechnology Research Asia, 11(30), 1563-1571 (2014)

15. M. Schilling, C. Phelps, Management science, 53, 1113-1126 (2007)

16. L. Serkov, Bulletin of the Chelyabinsk State University. Economy, 9(147), 113-117 (2009)

17. E.A. Shemetov, Modern problems of science and education (2015). http://www.scienceeducation.ru/101-5331

18. E.Yu. Tsyura, Mining information and analytical bulletin (scientific and technical journal), 8, 175-179 (2006).

19. I. Wilkinson, L. Young, Journal of Business Research, 55, 123-132 (2002)

20. S.V. Zdolnikova, A.V. Babkin, St. Petersburg State Polytechnical University Journal. Economics, 2(240), 78-86 (2016) 